\title{
Functional model of rat thyroid follicles cultured in Matrigel
}

\author{
Antonina Khoruzhenko ${ }^{1,2}$, Françoise Miot ${ }^{1}$, Claude Massart ${ }^{1}$, Jacqueline Van Sande ${ }^{1}$, Jacques Emile Dumont ${ }^{1}$, \\ Renaud Beauwens ${ }^{3}$ and Alain Boom ${ }^{4}$
}

${ }^{1}$ Institute of Interdisciplinary Research (IRIBHM), Université libre de Bruxelles, Brussels, Belgium

${ }^{2}$ Institute of Molecular Biology and Genetics, NAS of Ukraine, Kiev, Ukraine

${ }^{3}$ Laboratory of Physiology and Pharmacology, Université libre de Bruxelles, Brussels, Belgium

${ }^{4}$ Laboratoire d'Histologie, de Neuroanatomie et de Neuropathologie, Université libre de Bruxelles, Brussels, Belgium

Correspondence should be addressed to A Boom: aboom@ulb.ac.be

\begin{abstract}
Background: Long-term maintenance of functional activity of thyroid cells is an essential requirement for basic in vitro studies on the physiology and pathology of the thyroid. An important prerequisite of thyrocytes' functional activity in vivo and in vitro is their follicle organization.

Aim: This study aimed at developing a method of cultivation of functionally active rat thyroid follicles in Matrigel under three-dimensional conditions.

Methods: Undamaged rat thyroid follicles were isolated by enzymatic digestion with collagenase/dispase, then embedded into Matrigel, and cultivated for 2 weeks.

Thyroglobulin, thyroxine and zonula occludens-1 (ZO-1) localization were revealed by immunofluorescence analysis. Iodide organification was tested by protein-bound ${ }^{125}$ I (PBI) measurement.

Results: Integrity of the follicles was preserved during the whole period of cultivation and was confirmed by 3D reconstruction of ZO-1 localization. Thyroglobulin was detected in the thyrocyte cytoplasm, as well as in the intrafollicular lumen. Thyroxine was observed predominantly at the apical side of thyrocytes. Also, generated cultures were characterized by a high level of iodide organification: $\mathrm{PB}^{125}$ I represented $39 \%$ of the total radioactivity in the Matrigel drop embedding the follicles; at the same time, methimazole almost totally inhibited this process ( $0.2 \%$ of total radioactivity).

Conclusion: The method of rat thyrocyte cultivation in Matrigel, as described here allows to maintain the structural integrity and the functional activity of thyroid follicles in vitro and could be used for wide ranges of basic and applied researches in thyroidology.
\end{abstract}

\section{Key Words}

- three-dimensional culture of thyroid follicles

- thyroglobulin

- 125 organification

- thyroxine

\section{Introduction}

Thyroid cell cultures are widely used to study the basic mechanisms of the gland function, as well as to investigate the processes of carcinogenesis, sensitivity to drugs, toxicological studies, and others. The functional activity of thyroid follicles is closely related to their structural organization (1). Polarization of thyrocytes plays a key role in the production of the thyroid hormones. Therefore, until now, numerous in vitro cellular models were developed, which allow to maintain the essential properties of thyroid gland including cell polarization, intercellular contacts, the presence of intrafollicular lumens, etc. (2). It was previously shown that under conditions of monolayer culture, thyrocytes often lose their functional activity (3), although several functions were sometimes preserved $(4,5)$. The application of Transwell ${ }^{\circledR}\left(\operatorname{Costar}^{\circledR}\right)$ cell culture inserts for thyrocyte monolayer culture enables
This work is licensed under a Creative Commons Attribution-NonCommercial 4.0 International License. ded from Bioscientifica.com at $04 / 26 / 2023$ 03:44:41AM 
to preserve a polarized state of these cells (6). So, the majority of models to study functionally active thyrocytes are based on three-dimensional cultures. To this end, four main approaches were used for thyrocyte culture: (a) isolation of the whole follicles of functionally active thyrocytes from human/mammalian thyroid tissue with their subsequent cultivation, (b) reconstruction of folliclelike structure by the cells originating from the thyroid gland in three-dimensional conditions, (c) generation of thyroid follicles from stem cells in vitro and (d) application of primary organ culture. Each of these approaches has its own advantages and limitations. The benefits of the first approach (a) include the preservation of the original thyroid histoarchitectonics, namely homotypic intercellular contacts, intrafollicular lumen structure, maintenance of polarization, and high functional activity of the initial cells $(7,8,9)$. However, in this case, it is necessary to choose suitable culture conditions that could support long-term functional activity of follicular cells, including the optimal concentration of TSH, iodide salts, and growth factors. In addition, considering the activity of peroxidases (10), it is necessary to provide a balance of factors that control the formation of superoxide radicals. An important requirement for maintaining the polarity (apical localization of microvilli, presence of basal lamina, etc.) and functional activity of thyroid follicles in vitro is the adhesion of thyrocyte to the extracellular matrix (11). Of importance, a shortcoming of this approach is the restriction on the availability of large laboratory animals and postoperative healthy human material. A number of successful studies have been performed on cultures of follicles derived from the pig thyroid, but pigs, like some other large animals, are not always available, due to restrictions related to bioethical standards (12). Moreover the signalling pathway evoked by TSH apparently differs between pigs and humans or rats (13). Mouse, the most common laboratory animal, has a very small thyroid gland and, therefore, is not entirely suitable for this method. Some researches were carried out on primary cultures of rat thyroid follicles. Mainly, suspension cultures of rat follicles were used $(6,14)$. But in the absence of contact with the extracellular matrix, the phenomenon of follicle reversion takes place (11). Therefore, the presence of an extracellular lattice seems preferable.

Mentioned approach (a) could be also applied to study the fate of the luminal plasma membrane of thyroid follicles in connection to thyroglobulin endocytosis. For this study, the isolated follicles were opened to permit several agents to access the apical membrane to model the process of internalization and endocytosis (15).
Another approach (b) involves the reconstruction of the follicular organization in three-dimensional conditions by cells derived from the thyroid gland. Small cell aggregates from porcine thyrocyte suspension were restructured in reversed follicles in suspension culture. Normal thyroid polarity could be restored after embedding these follicles into collagen gel (16) or reconstituted basement membrane gel (17). It should be noted that regardless of the method of the primary thyroid culture initiation, either by using a suspension of isolated follicles or by a generation of follicles from suspended thyrocytes, the critical factor for maintaining proper polarization of follicles is the contact between the basement membrane of thyrocytes and extracellular matrix components $(11,16,17)$. In a recent study, the Fisher rat thyroid (FRT) cell line was shown to reproduce the normal architecture of follicles (18) but the expression of some key thyrocyte proteins necessary for their functional activity was appeared to be lost: the transcription factor Nkx2.1 (also called TTF-1) the thyrotropin receptor, thyroglobulin and the gap junction proteins (connexin 32 and 43) (19).

A protocol for generating thyroid follicles from mesenchymal stem cells (c) has been previously presented as well. These cells reproduced the original follicular structure and contained luminal thyroglobulin. The generation of such cultures is quite difficult and takes about 3 weeks (20). At present time, the technique of obtaining thyroid organoids in three-dimensional conditions seems promising. According to a recent study, the thyrocytes in such cultures are able to synthesize thyroglobulin and to take up radioactive iodide (21).

Organ cultures of the thyroid gland (d) are rarely used. These cultures retain the original follicular structure, heterotypic interactions and functional activity of thyrocytes, but their main limitation is their short survival in culture $(22,23)$. To overcome this problem, it was proposed to modify the culture conditions. Namely, pieces of mouse thyroid were cultured at $50 \%$ oxygen in the gas phase, and $5.6 \mathrm{M}$ of D glucose in the growth medium. This modification of the culture conditions allowed to keep the mini organs structures without disturbances for several weeks (24). Also, there is a method for the maintenance of functional thyroid follicles to determine the thyroid hormone effect on a target tissue. Actually, it has been shown that thyroid follicles transplanted via the portal vein into the liver of rats retained their histoarchitecture and functional activity up to 18 months and caused significant histochemical alterations of liver acini (25).

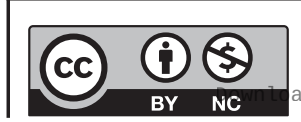

This work is licensed under a Creative Commons Attribution-NonCommercial 4.0 International License. ed from Bioscientifica.com at 04/26/2023 03:44:41AM 
Thus, the development of cell cultures for the study of physiology and pathology of the thyroid gland remains an important issue in experimental thyroidology. It is important to note that in addition to the structural organization of the thyroid parenchyma, an important role in the functioning of this gland is played by the stroma, primarily the network of blood vessels that tightly entwine the follicles. Moreover, the angiofollicular unit - a follicle with adjacent capillaries - is considered as a structurally functional unit of the thyroid gland (26). Because of that the development of organotypic cultures including thyroid follicles and blood vessel analogs could be a perspective direction of primary thyroid culture modification. Local differences in blood flow between different angiofollicular units most probably explain their different states of activity on which we didn't focus in the present study.

We propose here a functional model of rat thyroid follicles cultured in Matrigel. It has several important advantages: suspension of purified follicles is obtained by a simple procedure of double filtration using meshes with different pore size; structurally integral and functionally active thyroid follicles could be used for the experiment after 1 day of culture adaptation; cultured follicles retain their functional activity during at least 2 weeks, it is possible to carry out morphological/immunofluorescence analysis of cultured follicles.

In the present work, we have implemented and characterized a method of cultivation of rat thyroid follicles in growth factors reduced Matrigel. Optimal conditions of enzymatic disaggregation of the thyroid tissue and subsequent purification of the follicle suspension were selected. Also, the composition of the growth medium and the conditions of cultivation in Matrigel were optimized, which allowed to cultivate the follicles for at least 2 weeks. Morphological analysis revealed preservation of the follicular organization of thyrocytes. Their functional activity was confirmed by the presence of thyroglobulin, thyroxine (T4) as well as their ability to organify iodide.

\section{Materials and methods}

\section{Generation of rat thyroid follicle culture}

The various steps of the present procedure of rat thyroid follicles culture are summarized in Fig. 1. Two male Wistar rats (4-6 weeks, 140-160 g) were sacrificed by intraperitoneal injection of Nembutal. The lobes of thyroid glands were excised and placed into sterile tubes with Dubelcco's phosphate buffered saline (DPBS, Gibco \# 1400133, Thermo Fisher Scientific) containing: $\mathrm{Ca}^{2+} 0.9 \mathrm{mM}, \mathrm{Mg}^{2+} 0.49 \mathrm{mM}$, penicillin 500 units $/ \mathrm{mL}$, streptomycin $500 \mu \mathrm{g} / \mathrm{mL}$ (Gibco \#15070063). All subsequent procedures were carried out in sterile conditions. In a laminar hood, the thyroid lobes were transferred (by pipette) into petri dishes with basal eagle medium (BME), supplemented with penicillin 250 units/ $\mathrm{mL}$, streptomycin $250 \mu \mathrm{g} / \mathrm{mL}$, amphotericin B (Gibco \# 152900) $1 \mu \mathrm{g} / \mathrm{mL}$, fetal bovine serum 5\% FBS (Gibco \# 10270106) and were freed where it was possible from the fibrous capsule. The thyroid tissue was cut manually into small fragments $(1.0-1.5 \mathrm{~mm})$ which were transferred into a $15 \mathrm{~mL}$ tube and rinsed twice with $10 \mathrm{~mL}$ DPBS. After DPBS aspiration, the first portion $(4-5 \mathrm{~mL})$ of prewarmed enzyme mixture (collagenase $0.8 \mathrm{mg} / \mathrm{mL}$ (Sigma Cat\# C9891)), dispase $3 \mathrm{mg} / \mathrm{mL}$ (Sigma Cat\# D4693), trypsin inhibitor $0.4 \mathrm{mg} / \mathrm{mL}$ (Sigma Cat\# T6522) in DPBS was added to the tissue. The tube was placed horizontally and incubated for $20 \mathrm{~min}$ at $37^{\circ} \mathrm{C}$ with soft shaking every $5 \mathrm{~min}$. The enzyme mixture with a lot of debris was removed, and the pieces of thyroid tissue were incubated in 4-5 $\mathrm{mL}$ of fresh enzymes for another $10-15 \mathrm{~min}$ at $37^{\circ} \mathrm{C}$ with shaking every $4-5 \mathrm{~min}$. Isolated follicles were observed after placing the tube under the microscope. When the quantity of undamaged follicles was high enough, they were collected. A fresh portion of enzyme mixture $(4-5 \mathrm{~mL}$ ) was added to the remaining pieces and incubated in the same conditions until complete dissociation of the tissue pieces. Thereafter the collected follicles were passed through a polyethylene terephthalate (PET) filter of $200 \mu \mathrm{m}$ pore diameter (PluriSelect 43-50200-03). BME medium supplemented with 5\% FBS, penicillin 50 units $/ \mathrm{mL}$, streptomycin $50 \mu \mathrm{g} / \mathrm{mL}$, amphotericin B $1 \mu \mathrm{g} / \mathrm{mL}$ was used to rinse the filter. Then the follicles were collected on the filter of $40 \mu \mathrm{m}$ pore diameter (PluriSelect 43-50040-51) and washed with the same medium. The follicles retained on the mesh with pores $40 \mu \mathrm{m}$ were washed away from the filter into a petri dish by flushing some of the same medium. The quantity of follicles was examined under the microscope (Fig. 1, panel B), and the follicles were then put into a tube. To reach the complete dissociation of thyroid tissue, the procedure was repeated three to five times, yielding the follicle suspension used for culture.

Cover glasses of $15 \mathrm{~mm}$ diameter were preliminarily treated with $50 \mathrm{~mL}$ of $1 \mathrm{~N} \mathrm{HCl}$ for $1 \mathrm{~h}$ at room temperature, rinsed three times with $100 \mathrm{~mL}$ of milliQ $\mathrm{H}_{2} \mathrm{O}$, rinsed two times with $96 \%$ ethanol, air-dried, autoclaved and dried at $80^{\circ} \mathrm{C}$. Before culture initiation, the cover glasses 


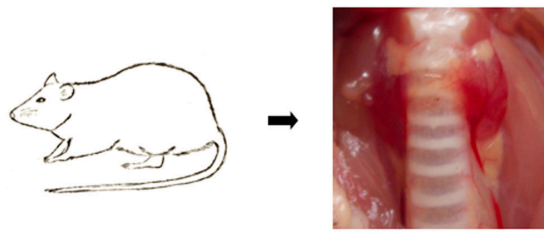

Rat

\section{Rat thyroid}

\section{$\underset{\text { Collagenase }}{\diamond} \nabla$ \\ dispase}

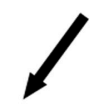

Filtration

1 ) $200 \mathrm{mkm}$

$\left.2^{\circ}\right) 40 \mathrm{mkm}$
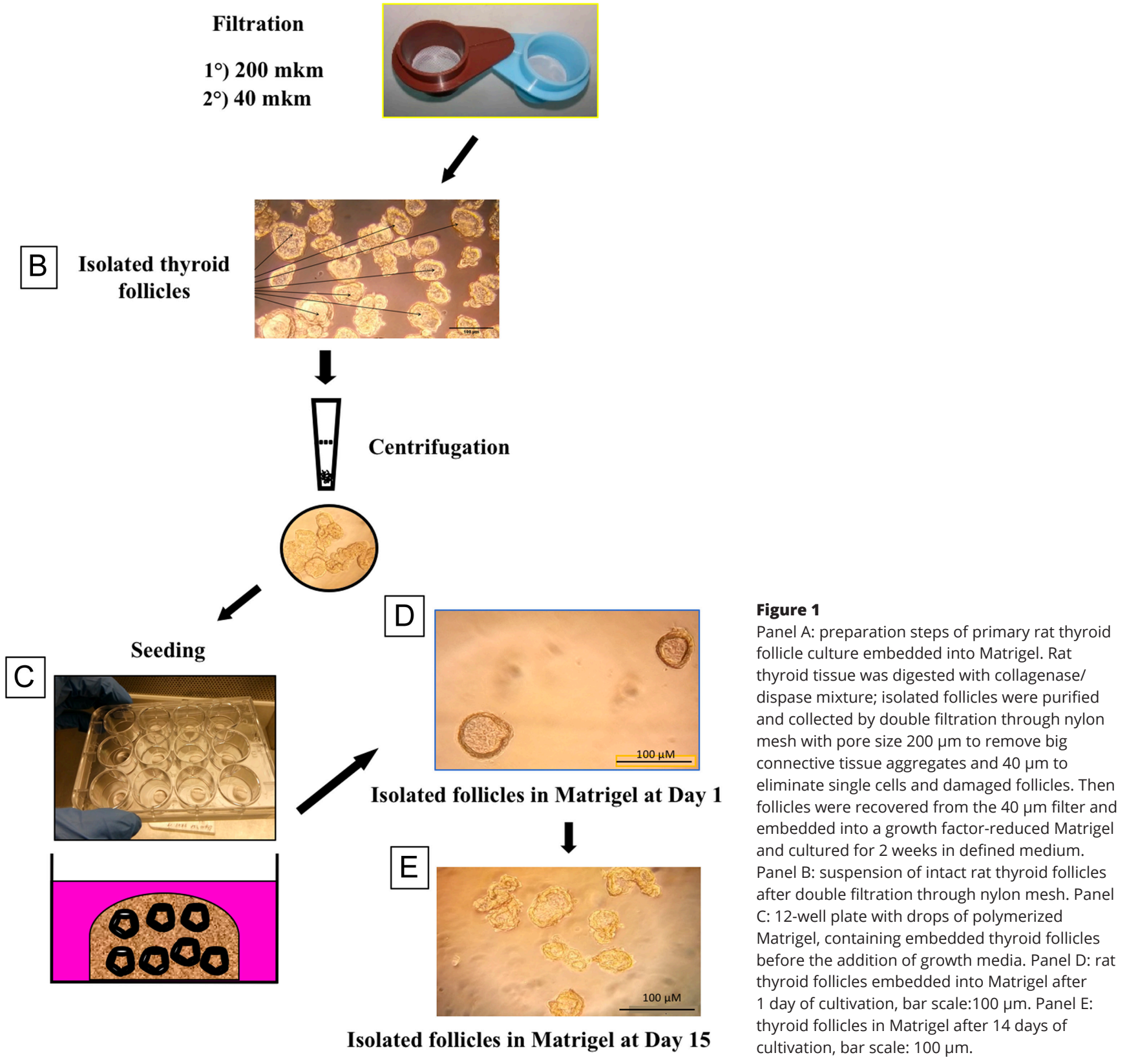

were put into a 12-well plate and the center of each glass was covered by $25 \mu \mathrm{L}$ of growth factor reduced Matrigel (Corning 354230) to form a round dot of about $0.7-1 \mathrm{~cm}^{2}$. The plate was placed into a $5 \% \mathrm{CO}_{2}$ incubator for $18 \mathrm{~min}$ at $37^{\circ} \mathrm{C}$ to polymerize the Matrigel.
Follicle suspension was centrifuged for $3.5 \mathrm{~min}$ at $300 \mathrm{~g}$. After centrifugation, the supernatant was discarded and the tube with follicles was placed on ice. Five hundred microliters of Matrigel was added to the follicles and they were resuspended by gentle aspiration through 
$1.25 \mathrm{~mL}$ tip (Nest 304016). Thirty-five microliters of follicle suspension in Matrigel was added into each well onto the dot of already solidified Matrigel and incubated in $\mathrm{CO}_{2}$ incubator at $37^{\circ} \mathrm{C}$ for $20 \mathrm{~min}$ (Fig. 1, panels $\mathrm{C}$ and $\mathrm{D}$ ).

The growth medium was as follows: F12 Coon's modified medium (Gibco Cat.\# 04191295M) enriched with 5\% FBS; growth medium supplement (GMS): L-glutamine (Gibco Cat.\#25030024) $2 \mathrm{mM}$, penicillin $50 \mathrm{U} / \mathrm{mL}$, streptomycin $50 \mu \mathrm{g} / \mathrm{mL}$, amphotericin B $1 \mu \mathrm{g} / \mathrm{mL}$, transferrin $5 \mu \mathrm{g} / \mathrm{mL}$ (Sigma Cat.\# T8150), insulin $10 \mathrm{ng} / \mathrm{mL}$ (Sigma Cat.\# I0516), potassium iodide $10 \mathrm{nM}$ (Merck Cat.\#.105044), glutathione $5 \mathrm{mg} / \mathrm{L}$ (Sigma Cat.\# G4251), L-ascorbic acid $5 \mathrm{mg} / \mathrm{L}$ (Merck Cat.\#.A4403), bovine TSH $1 \mathrm{mU} / \mathrm{mL}$ (Sigma Cat.\# T8931) (27). Two microliters of growth medium was added into each well and changed every other day.

Several compositions of culture medium and growth medium supplement were tested to choose the optimal for prolonged cultivation of thyroid follicles in growth factor depleted Matrigel: (i) RPMI+GMS, (ii) F12 Coon's modified+GMS, (iii) RPMI+0.1\% FBS +GMS, (iv) F12 Coon's modified $+0.1 \%$ FBS + GMS, (v) RPMI + 1\% FBS, (vi) F12 Coon's modified + 5\% FBS+ GMS.

After 14 days of cultivation, the samples on cover glasses were fixed for $3.5 \mathrm{~h}$ at room temperature by $4 \%$ buffered formaldehyde (Fig. 1 panel E) and finally were stored at $4^{\circ} \mathrm{C}$ in PBS.

\section{Immunofluorescence analysis}

\section{Agarose block preparation}

Hundred milliliters of PBS containing 4\% agarose (Sigma Cat.\# A9539) solution was melted at $100^{\circ} \mathrm{C}$ and shaked on a magnetic stirrer. Five milliliters of agarose was put into each mold (Polysciences Cat\# 18646A-1) and incubated in a water bath for $15-20 \mathrm{~min}$ at $65^{\circ} \mathrm{C}$. Cover glasses with fixed follicles in Matrigel were placed onto a microscope slide and air-dried for 10-12 min. Then, the samples were put into the molds with agarose and incubated for an additional $15-20 \mathrm{~min}$ at $65^{\circ} \mathrm{C}$. The molds were removed from the water bath and incubated at room temperature for $5 \mathrm{~min}$. Then, $5 \mathrm{~mL}$ of boiled agarose was added to each mold. The samples were incubated for $2 \mathrm{~h}$ at room temperature and kept in a refrigerator at $4^{\circ} \mathrm{C}$.

\section{Preparation of agarose slices}

Excess agarose was cut from agarose block and the sample was glued to the holder of the vibratome (Leica VT1000S) with acrylic glue. Vibratome cuvette was filled with PBS.
The cutting was performed at speed 5 and frequency 6 , with a slice thickness of $100 \mu \mathrm{m}$. Slices were collected by a tassel and put in 24 well-plates containing PBS.

\section{Immunofluorescence analysis}

Immunofluorescence analysis on agarose slices was carried out in a 24-well plate. Nonspecific binding blockade and antigen availability were provided by slice treatment with blocking solution (3\% BSA, 5\% horse serum, $0.15 \%$ Triton $\mathrm{X}-100$ in PBS) for $40 \mathrm{~min}$ at room temperature. Antibodies were diluted in a solution composed of 3\% BSA, 1\% horse serum, $0.1 \%$ Triton $\mathrm{X}-100$, in PBS. Incubation with primary antibody was performed overnight at $4^{\circ} \mathrm{C}$ at slow rotation, in a $250-400 \mu \mathrm{L} /$ well. The following antibody dilutions were applied: mouse anti-thyroglobulin antibody 1:250 (Abcam \# ab187378), rabbit anti-thyroglobulin antibody 1:3000 (Dako \#A0251), rabbit anti-ZO-1 antibody 1:500 (Invitrogen Cat\# 40-2200), goat anti-T4 antibody 1:500 (Biorbyt \#orb11479) followed by three times washing with PBS ( $2 \mathrm{~mL} /$ well for $10 \mathrm{~min}$ under gentle agitation). Secondary antibodies anti-mouse FITC488 1:300 (Abcam Cat\# ab150113), anti-mouse Alexa Fluor 594 1:300 (Invitrogen Cat\# A11032), anti-mouse Cy5 1:500 (Invitrogen Cat\#A10524), anti-rabbit Alexa Fluor 555 1:500 (Invitrogen Cat\# A27039), Cy3 conjugated antigoat 1:500 (Jackson \#705-165-147) were incubated for $1 \mathrm{~h} 40 \mathrm{~min}$ at room temperature under slow agitation. DNA was counterstained with DAPI (Sigma Cat\# D9564) for $20 \mathrm{~min}$ RT. Slices were embedded into glycergel (Agilent Dako Cat\# C0563) supplemented with $25 \mathrm{mg} / \mathrm{mL}$ DABCO (Sigma Cat\# D27802) and covered by cover glasses. DABCO was used as an anti-fading agent since follicle preparations are rather thick and could be damaged by photobleaching during confocal imaging. Images were taken using a confocal microscope Zeiss 510 Meta.

\section{lodide uptake assay}

The scheme of the procedure is presented in Fig. 2. The culture of rat thyroid follicles was initiated as described above. After $24 \mathrm{~h}$ of incubation, the growth medium was changed for fresh medium but the KI concentration was increased to $1 \mu \mathrm{M}$. The growth medium was changed every other day. On day 10, the medium was supplemented with $0.5 \mu \mathrm{Ci} / \mathrm{mL}$ of ${ }^{125}$ I (Perkin Elmer Cat\# NEZ033001MC), added to all wells. Methimazole (MMI) $1 \mathrm{mM}$, a thyroperoxidase inhibitor, was added to control wells to measure the background of the method. On day 14,

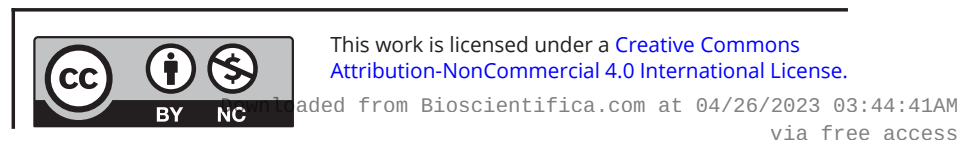




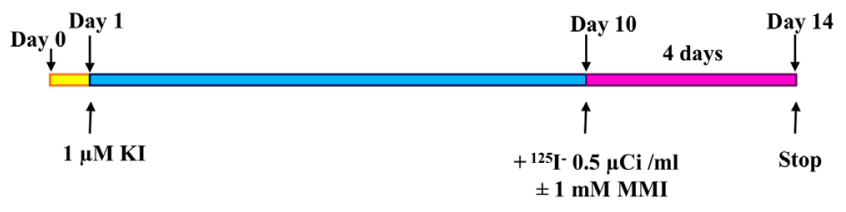

$\mathrm{PB}^{125} \mathrm{I} /$ total $^{125} \mathrm{I}$ in the Matrigel drop $\mathrm{x}$ 100. $(\mathrm{n}=5)$

\begin{tabular}{|c|c|}
\hline control & + MMI $(1 \mathrm{mM})$ \\
\hline $39.2 \pm 5.6$ & $0.23 \pm 0.06$ \\
\hline
\end{tabular}

\section{Figure 2}

Scheme for experimental detection of ${ }^{125}$ I organification measured by protein-bound iodine test (PBI) in rat thyroid follicles cultured for 2 weeks in Matrigel. PBI values are expressed as the ratio of PB ${ }^{125}$ | to total ${ }^{125}$ in the Matrigel drop $\times 100$; mean \pm S.E.M. of five different preparations.

${ }^{125}$ I uptake was stopped by discarding and rinsing the wells with $2 \mathrm{~mL}$ of $2 \mathrm{mM}$ MMI in PBS. Follicles were recovered by digestion of the Matrigel (see enzyme mixture for follicle isolation from tissue) supplemented with $2 \mathrm{mM}$ MMI in $\mathrm{PBS}$ at $37^{\circ} \mathrm{C}$ for $15 \mathrm{~min}$. After gentle pipetting by blue tip, the suspension of follicles was transferred into a tube for $\mathrm{I}^{125}$ uptake measurement. The well was washed with $1 \mathrm{~mL}$ PBS containing $2 \mathrm{mM}$ MMI added to the same tube and the radioactivity was measured in a gamma counter (Perkin Elmer Wizard1470 Automatic Gamma Counter) as total ${ }^{125} \mathrm{I}$ in the Matrigel drop containing the follicles. For estimation of protein-bound iodine (PBI), after digestion of the Matrigel with enzyme mixture (collagenase $0.8 \mathrm{mg} / \mathrm{mL}$, dispase $3 \mathrm{mg} / \mathrm{mL}$, and trypsin inhibitor $0.4 \mathrm{mg} / \mathrm{mL}$ in DPBS), $2 \mathrm{~mL}$ of 20\% TCA (trichloroacetic acid) was added to each tube to precipitate the proteins. Samples were centrifuged for $10 \mathrm{~min}$ at $450 \boldsymbol{g}$ and the pellet was resuspended in $4 \mathrm{~mL}$ of $10 \%$ TCA. Protein precipitation and washing were repeated twice. Organified ${ }^{125} \mathrm{I}$ was estimated by counting the radioactivity in the washed pellet in a gamma counter. Data were expressed as the ratio of bound ${ }^{125}$ I to total ${ }^{125} \mathrm{I}$ in the Matrigel drop $\times 100$.

\section{Ethic statement}

Rats were anesthetized with Nembutal in compliance with and after approval of the Ethical and Animal Welfare Committee of the Université libre de Bruxelles (protocol number \#709N).

\section{Results and discussion}

The maintenance of functionally active thyroid cells in vitro is required for a variety of biomedical investigations.
The follicle-like organization of cultured thyrocytes is a necessary condition for the preservation of the functional activity of these cells. Figure 1 represents the scheme of rat thyroid processing to isolate undamaged follicles and ready to be embedded in Matrigel. Mild enzyme treatment with several collections of whole follicles and regular visual control of the obtained material ensured the harvest of suspension of undamaged follicles. Also, supplementing a collagenase/dispase mixture with trypsin inhibitor decreased the nonspecific protease activity and contributed to the preservation of the integrity of a follicular structure. Double filtration of the follicle suspension provided the elimination of crude connective tissue aggregates and small or damaged follicles. It should be noted that in some wells, the fibroblasts from thyroid stroma were present as well and they could produce connective tissue like fibers inside Matrigel. These fibroblasts did not alter the structure of the cultured thyroid follicles.

It is also necessary to monitor the efficiency of recovering the follicles from the $40 \mu \mathrm{m}$ filter. The best way to wash follicles from the filter was to touch the turned filter with a pipette and apply a gentle stream of liquid. Insufficient washing of the filter led to the loss of a significant quantity of the follicles. Therefore, this step should be performed in a petri dish, which allows to assess the number of follicles by using a microscope.

To minimize the effect of growth factors on the culture of thyroid follicles, growth factor depleted Matrigel was applied. An important step for follicle structure preservation consists of precoating the cover glasses with Matrigel. It completely prevented the spreading of thyroid follicles by abolishing their contact with cover glass.

Several compositions of culture medium and growth medium supplement were compared to detect the most suitable conditions for prolonged cultivation of thyroid follicles in Matrigel. F12 Coon's modified medium $+5 \%$ FBS + GMS was chosen as the optimal combination, based on the morphological assay of thyroid follicles after 2 weeks of cultivation.

To examine the morphological features of cultured rat thyroid follicles, the immunofluorescence analysis was used. First of all, the presence of thyroglobulin in the follicular cells was revealed. It should be noted that the use of antibodies to thyroglobulin of various origins allowed to detect the thyroglobulin in both cytoplasmic and the intrafollicular lumen. Namely, mouse monoclonal anti-thyroglobulin antibody Abcam ab187378 (Fig. 3) recognized thyroglobulin mainly in the cytoplasm of thyrocytes, while rabbit 


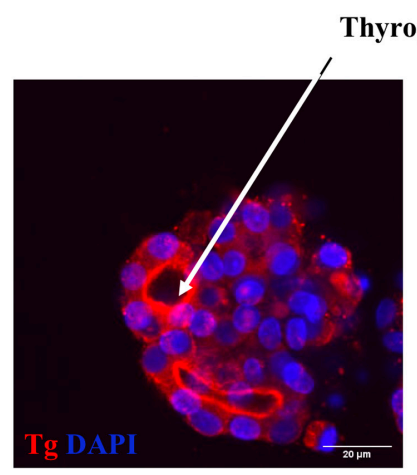

Mouse monoclonal anti-Tg antibody Abcam ab187378

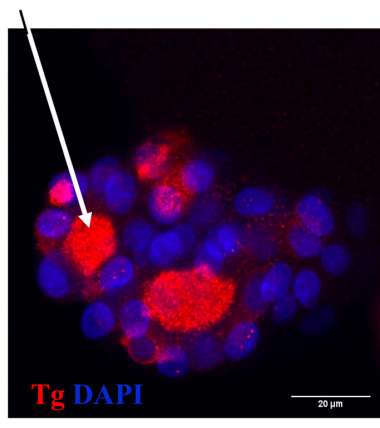

Rabbit polyclonal anti-Tg antibody Dako A0251

Figure 3

Immunofluorescence detection of thyroglobulin content in thyroid follicles embedded in Matrigel after 2 weeks of cultivation. Mouse monoclonal anti-Tg antibody ab187378 revealed mainly cytoplasmic thyroglobulin (red) whereas rabbit polyclonal anti-Tg antibody Dako A0251 detected thyroglobulin predominantly in intrafollicular lumen (red). Nuclei counterstained with DAPI (blue), bar scale: $20 \mu \mathrm{m}$.

polyclonal anti-thyroglobulin antibody Dako A0251 showed predominantly intrafollicular localization of thyroglobulin on the serial slices of the same sample. It could be hypothesized that these antibodies react with different epitopes of thyroglobulin. Such epitopes could be more or less accessible in thyroglobulin molecules depending on its actual status, for example, partial proteolysis. Indeed, 'the cytoplasmic thyroglobulin' that was observed during all the period of cultivation (Fig. 4) is most probably contained within vesicles, either 'en route' to the follicular lumen (exocytic vesicle containing newly synthesized thyroglobulin) or on the contrary within endocytic vesicles just removed from the follicular lumen. We have no way to distinguish between these possibilities and most probably they both coexist particularly in the presence of $1 \mathrm{mU} / \mathrm{mL}$ TSH. In the case of endocytic vesicles, newly added enzymes from peripheral lysosomes may have uncovered new epitopes that are not accessible within the colloid. Indeed thyroglobulin hydrolysis is a complex process sensitive to thyrotropin and mediated at least by three different cathepsins B, D

and L. These reactions can uncover some new epitopes. Furthermore, T4 generation was confirmed by a bright positive immunofluorescence reaction predominantly located at the apical membrane of follicular cells (Fig. 5). However, we can only guess whether T4 is free or bound to thyroglobulin. The colocalization of both T4 and $\mathrm{Tg}$ may suggest that $\mathrm{T} 4$ is still bound within $\mathrm{Tg}$ at the apical domain but the lack of colocalization within the colloid may indicate the opposite. Thus, we cannot definitively rule out that the bright immunofluorescence is a reflection of multiple intravesicular T4 molecules released from thyroglobulin but still contained within the same vesicles while after going through the vesicle or lysosomal membrane, free $\mathrm{T} 4$ within the cytoplasm would be more diffused and not anymore bright at the basal pole.

Apical localization of ZO-1-positive tight junction protein was observed in cultured rat thyroid follicles by immunofluorescence analysis (Fig. 6). Moreover, the application of confocal microscopy and 3D reconstruction allowed to confirm the integrity of cultured follicles (Fig. 7). Three-dimensional reconstruction revealed the honeycomb pattern of the ZO-1 distribution at thyrocyte lumen-facing apical membrane as occurring in vivo (28).

Also, the size of follicles after 1 and 14 days of cultivation was valued. It was determined that after 1 day of cultivation, the mean follicle diameter was $45.88 \pm 13.25 \mu \mathrm{m}$. The minimum diameter was about $30 \mu \mathrm{m}$ and the maximum was $72 \mu \mathrm{m}$. The presence of some quantity of small follicles (less than $40 \mu \mathrm{m}$ ) could be explained by the following reason: the groups of small follicles were retained on $40 \mu \mathrm{m}$ filter and then, they were disaggregated at the subsequent step, namely, during pipetting of follicles in Matrigel before they were put into 12-well plate. Also, sometimes, we observed such groups of small follicles in our cultures. The diameter of rat thyroid follicles after 14 days of cultivation was $47.57 \pm 12.74$. There was no statistically significant difference between the follicle size after 1 and 14 days of cultivation ( $t$-test, GraphPadPrism 6.01).
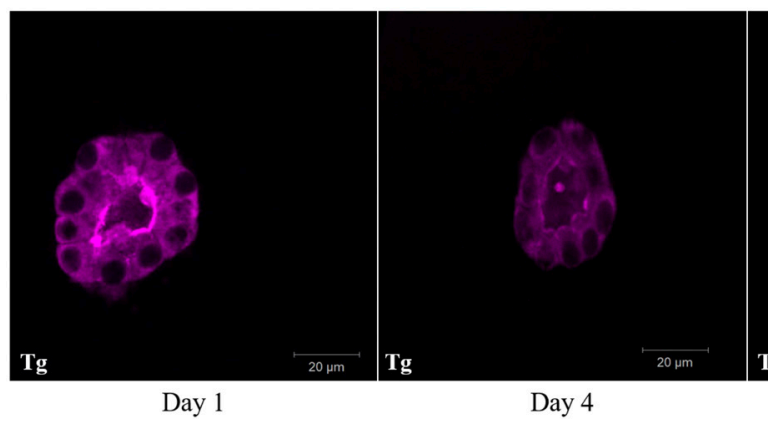

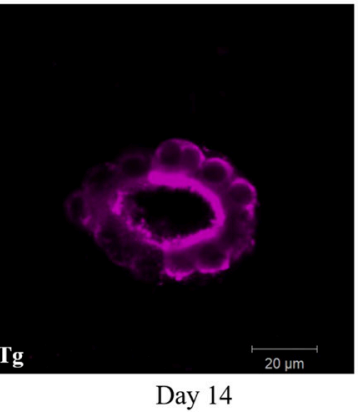

\section{Figure 4}

Immunofluorescence analysis of thyroglobulin content (purple) in rat thyroid follicles after 1, 4, and 14 days of cultivation in Matrigel, bar scale: $20 \mu \mathrm{m}$. https://ec.bioscientifica.com https://doi.org/10.1530/EC-21-0169 (c) 2021 The authors Published by Bioscientifica Ltd

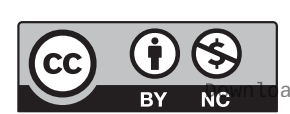

This work is licensed under a Creative Commons Attribution-NonCommercial 4.0 International License. ded from Bioscientifica.com at 04/26/2023 03:44:41AM 


$\mathbf{5 7 7}$

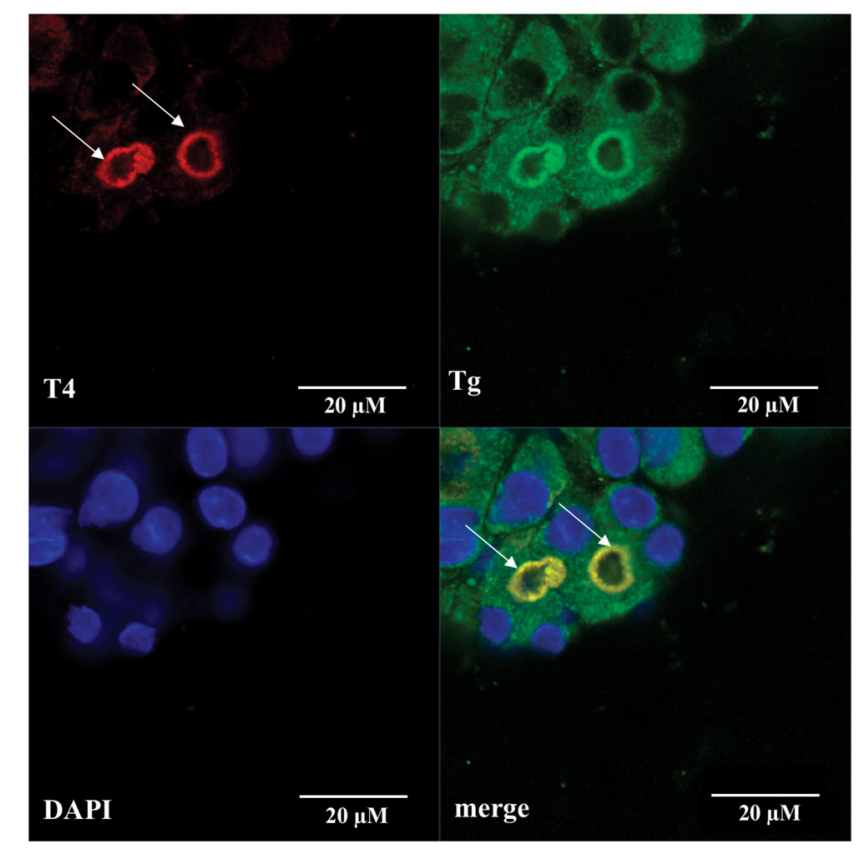

Figure 5

Immunofluorescence detection of T4 (red) and thyroglobulin (green) content in rat thyroid follicles after 14 days of cultivation in Matrigel. Arrows point out bright intraluminal reaction at apical side of thyrocytes, also there is a weak cytoplasmic reaction for T4 in rat thyroid follicles. Nuclei counterstained with DAPI (blue), bar scale $20 \mu \mathrm{m}$.

As the organification of iodide is a major step in thyroid physiology, the uptake of ${ }^{125}$ Iwas tested in rat follicle cultured for 14 days in Matrigel following the protocol designed in Fig. 2. KI concentration up to $1 \mu \mathrm{M}$ was added on day 1 as a carrier and to stabilize the uptake of ${ }^{125} \mathrm{I}^{125} \mathrm{I}^{-}$, $0.5 \mu \mathrm{Ci} / \mathrm{mL} \pm \mathrm{MMI}$ was added on day 10 during 4 days. Follicles were isolated from Matrigel by enzyme digestion. The rest of the digested Matrigel served as protein carriers for subsequent re-precipitation of proteins, in order to reduce the loss of PBI. The uptake of ${ }^{125} \mathrm{I}$ by the follicles in presence of MMI was insignificant: the counted ${ }^{125}$ I uptake varies in the range of $0.05-0.4 \%$ (mean $0.23 \pm 0.06 \%$ ) of total radioactivity counted in the whole Matrigel drop. In contrast, in the absence of MMI, rat thyroid follicles cultured for 2 weeks in Matrigel actively transported and organified iodide. Radioactive iodide counted in the TCA precipitate represented $24.4-54.9 \%$ (mean $39.2 \pm 5.6 \%$ ) of the total radioactive iodide in the Matrigel drop. These data serve as convincing evidence that under the proposed experimental conditions, the follicular cells of the rat thyroid gland retain their functional activity.

In conclusion, we have developed a technique of primary rat thyroid follicle culture keeping its initial follicular organization and high functional activity of thyrocytes during 2 weeks of cultivation. The proposed

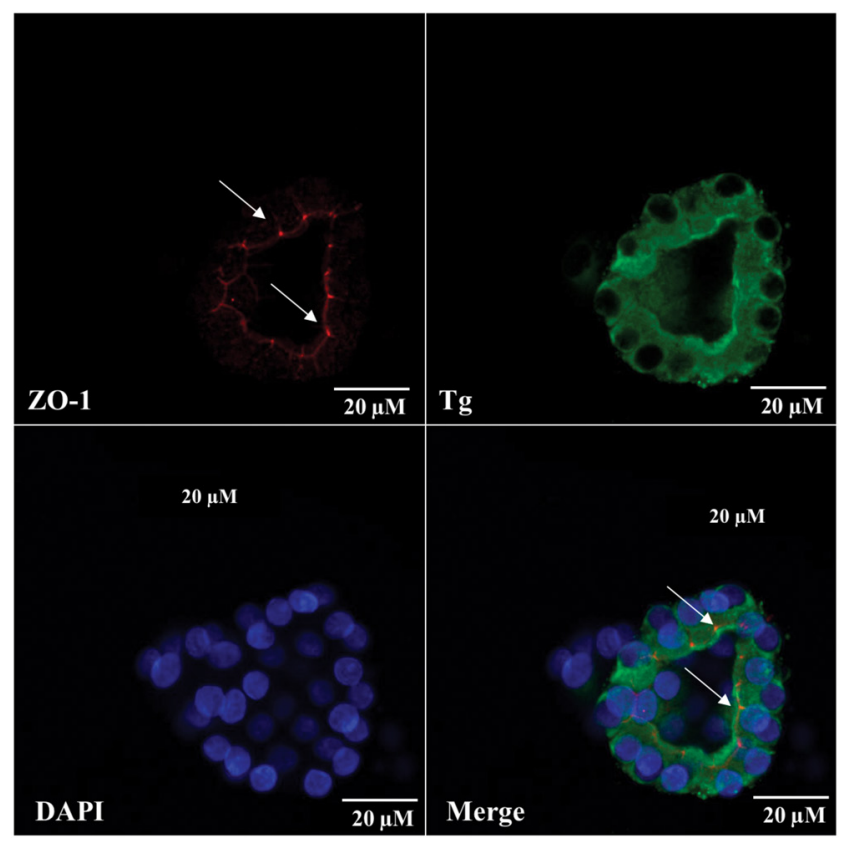

\section{Figure 6}

Immunofluorescence analysis of ZO-1 (red) localization and thyroglobulin (green) content in rat thyroid follicles after 14 days of cultivation in Matrigel. Arrows point out the bright apical reaction of ZO-1 in cultured thyrocytes. Nuclei counterstained with DAPI (blue), bar scale: $20 \mu \mathrm{m}$.

model will be useful for both research of the basic mechanisms underlying the functioning of the thyroid gland, and evaluation of the effect of different factors on the whole behavior and functional activity of thyroid cells.

\section{Declaration of interest}

The authors declare that this research was conducted in the absence of any financial or other potential conflict of interest.

\section{Funding}

This study was supported by the 'Fonds Dr Jean-Pierre Naet' (\#J1813300) managed by the 'Fondation Roi Baudouin', Belgium.
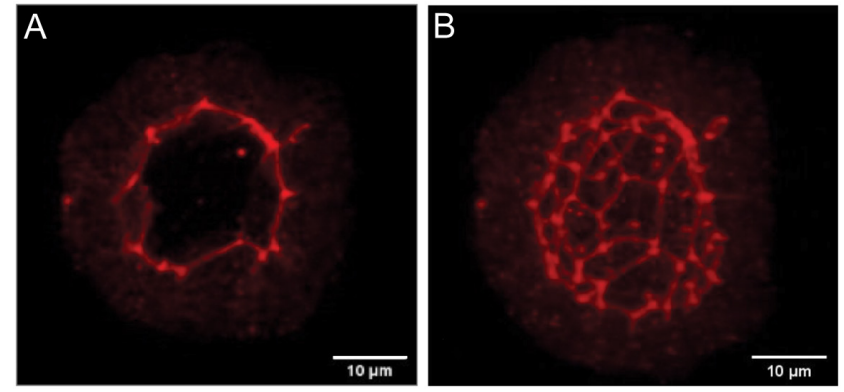

\section{Figure 7}

Immunofluorescence detection of ZO-1 (A) and 3D reconstruction of follicle structure based on consecutive confocal optical slices (B) confirm the integrity of follicles cultured in Matrigel. Bar scale:10 $\mu \mathrm{m}$. https://ec.bioscientifica.com https://doi.org/10.1530/EC-21-0169
This work is licensed under a Creative Commons Attribution-NonCommercial 4.0 International License. ded from Bioscientifica.com at 04/26/2023 03:44:41AM 
14 Simons PJ, Delemarre FG \& Drexhage HA. Antigen-presenting dendritic cells as regulators of the growth of thyrocytes: a role of interleukin-1 $\beta$ and interleukin-6. Endocrinology 1998139 3148-3156. (https://doi.org/10.1210/endo.139.7.6110)

1 Rousset B, Dupuy C, Miot F \& Dumont JE. Chapter 2. Thyroid hormone synthesis and secretion. In Endotext, Eds KR Feingold, B Anawalt, A Boyce, et al. South Dartmouth, MA, USA: MDText.com, Inc, 2015. (available at: https://www.ncbi.nlm.nih.gov/books/NBK285550)

2 Samimi H, Atlasi R, Parichehreh-Dizaji S, Khazaei S, Rahnama MA, Seifirad S \& Haghpanah V. A systematic review on thyroid organoid models: time-trend and its achievements. American Journal of Physiology: Endocrinology and Metabolism 2021320 E581-E590. (https://doi.org/10.1152/ajpendo.00479.2020)

3 Bocanera LB, Aphalo P, Pisarev MA, Gärtner R, Silberschmidt D, Juvenal GJ, Beraldi G \& Krawiec L. Presence of a soluble inhibitor of thyroid iodination in primary cultures of thyroid cells. European Journal of Endocrinology 1999141 55-60. (https://doi.org/10.1530/ eje.0.1410055)

4 Roger PP, Christophe D,Dumont JE \& Pirson I. The dog thyroid primary culture system: a model of the regulation of function, growth and differentiation expression by cAMP and other welldefined signaling cascades. European Journal of Endocrinology 1997 137 579-598. (https://doi.org/10.1530/eje.0.1370579)

5 Di Lauro R, Damante G, De Felice M, Arnone MI, Sato K, Lonigro R \& Zannini M. Molecular events in the differentiation of the thyroid gland. Journal of Endocrinological Investigation 199518 117-119. (https://doi.org/10.1007/BF03349716)

6 Pocard T, Le Bivic A, Galli T \& Zurzolo C. Distinct v-SNAREs regulate direct and indirect apical delivery in polarized epithelial cells. Journal of Cell Science 2007120 3309-3320. (https://doi.org/10.1242/jcs.007948)

7 Spinel-Gomez C, Colin I, van den Hove MF \& Denef JF. Correlated morphological and functional study of isolated rat thyroid follicles in suspension culture. Molecular and Cellular Endocrinology 199071 141-153. (https://doi.org/10.1016/0303-7207(90)90251-3)

8 Khoruzhenko A. New approaches for thyrocyte cultivation in vitro with retention of their follicular organization. Experimental Oncology 200224 99-104.

9 Sato K, Yamazaki K, Shizume K, Kanaji Y, Obara T, Ohsumi K, Demura H, Yamaguchi S \& Shibuya M. Stimulation by thyroidstimulating hormone and Grave's immunoglobulin $\mathrm{G}$ of vascular endothelial growth factor mRNA expression in human thyroid follicles in vitro and mRNA expression in the rat thyroid in vivo. Journal of Clinical Investigation 199596 1295-1302. (https://doi. org/10.1172/JCI118164)

10 Ghaddhab C, Kyrilli A, Driessens N, Van Den Eeckhaute E, Hancisse O, De Deken X, Dumont JE, Detours V, Miot F \& Corvilain B. Factors contributing to the resistance of the thyrocyte to hydrogen peroxide. Molecular and Cellular Endocrinology 2019481 62-70. (https://doi.org/10.1016/j.mce.2018.11.010)

11 Garbi C, Nitsch L \& Wollman SH. Embedding in a collagen gel stabilizes the polarity of epithelial cells in thyroid follicles in suspension culture. Experimental Cell Research 1984151 458-465. (https://doi.org/10.1016/0014-4827(84)90395-1)

12 Fröhlich E, Wahl R \& Reutter K. Basal lamina formation by porcine thyroid cells grown in collagen- and laminin-deficient medium. Histochemical Journal 199527 602-608. (https://doi.org/10.1007/ BF02388459)

13 Song Y, Massart C, Chico-Galdo V, Jin L, De Maertelaer V, Decoster C, Dumont JE \& Van Sande J. Species specific thyroid signal transduction: conserved physiology, divergent mechanisms. Molecular and Cellular Endocrinology 2010319 56-62. (https://doi. org/10.1016/j.mce.2010.01.024)
15 Herzog V \& Miller F. Membrane retrieval in epithelial cells of isolated thyroid follicles. European Journal of Cell Biology 197919 203-215.

16 Chambard M, Verrier B, Gabrion J \& Mauchamp J. Polarity reversal of inside-out thyroid follicles cultured within collagen gel: reexpression of specific functions. Biology of the Cell 198451 315-325. (https:// doi.org/10.1111/j.1768-322x.1984.tb00310.x)

17 Espanet H, Alquier C \& Mauchamp J. Polarity reversal of inside-out thyroid follicles cultured on the surface of a reconstituted basement membrane matrix. Experimental Cell Research 1992200 473-480. (https://doi.org/10.1016/0014-4827(92)90198-h)

18 Koumarianou P, Goméz-López G \& Santisteban P. Pax8 controls thyroid follicular polarity through cadherin-16. Journal of Cell Science 2017130 219-231. (https://doi.org/10.1242/jcs.184291)

19 Tonoli H, Flachon V, Audebet C, Callé A, Jarry-Guichard T, Statuto M, Rousset B \& Munari-Silem Y. Formation of three-dimensional thyroid follicle-like structures by polarized FRT cells made communication competent by transfection and stable expression of the connexin-32 gene. Endocrinology 2000141 1403-1413. (https://doi.org/10.1210/ endo.141.4.7400)

20 Antonica F, Figini Kasprzyk DF, Opitz R, Iacovino M, Liao XH, Dumitrescu AM, Refetoff S, Peremans K, Manto M, Kyba M, et al. Generation of functional thyroid from embryonic stem cells. Nature 2012491 66-71. (https://doi.org/10.1038/nature11525)

21 Saito Y, Onishi N, Takami H, Seishima R, Inoue H, Hirata Y, Kameyama K, Tsuchihashi K, Sugihara E, Uchino S, et al. Development of a functional thyroid model based on an organoid culture system. Biochemical and Biophysical Research Communications 2018497 783-789. (https://doi.org/10.1016/j.bbrc.2018.02.154)

22 Young BA \& Baker TG. The ultrastructure of rat thyroid glands under experimental conditions in organ culture. Journal of Anatomy 1982 135 407-412.

23 Asakawa H, Hanafusa T, Oda Y, Katsura H, Miyagawa J, Mashita K, Kono N \& Tarui S. Human recombinant interleukin 1 inhibits TSH-stimulated morphological changes in thyroid follicles cultured as semi-organs. Acta Endocrinologica 1991125 80-85. (https://doi. org/10.1530/acta.0.1250080)

24 Bauer MF \& Herzog V. Mini organ culture of thyroid tissue: a new technique for maintaining the structural and functional integrity of thyroid tissue in vitro. Laboratory Investigation 198859 281-291.

25 Dombrowski F, Klotz L, Hacker HJ, Li Y, Klingmüller D, Brix K, Herzog V \& Bannasch P. Hyperproliferative hepatocellular alterations after intraportal transplantation of thyroid follicles. American Journal 9440(10)64710-4)

26 Colin IM, Denef JF, Lengelé B, Many MC \& Gérard AC. Recent insights into the cell biology of thyroid angiofollicular units. Endocrine Reviews 201334 209-238. (https://doi.org/10.1210/er.20121015)

27 Bechtner G, Fröschl H, Sachse A, Schopohl D \& Gärtner R. Induction of apoptosis in porcine thyroid follicles by transforming growth factor beta1 and epidermal growth factor. Biochimie 199981 315-320. (https://doi.org/10.1016/s0300-9084(99)80076-5)

28 Rebuffat SA, Kammoun-Krichen M, Charfeddine I, Ayadi H, Bougacha-Elleuch N \& Peraldi-Roux S. IL-1 $\beta$ and TSH disturb thyroid epithelium integrity in autoimmune thyroid diseases. Immunobiology 2013218 285-291. (https://doi.org/10.1016/j. imbio.2012.05.016)

Received in final form 8 April 2021

Accepted 28 April 2021

Accepted Manuscript published online 28 April 2021 of Pathology 2000156 99-113. (https://doi.org/10.1016/S0002- https://ec.bioscientifica.com https://doi.org/10.1530/EC-21-0169 (c) 2021 The authors Published by Bioscientifica Ltd

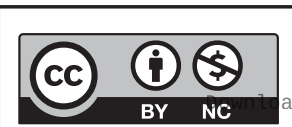

This work is licensed under a Creative Commons Attribution-NonCommercial 4.0 International License. ded from Bioscientifica,com at 04/26/2023 03:44:41AM 